\title{
Hyperplastic gastric polyposis complicated by a high-grade sarcomatoid malignancy
}

\author{
Hugh J Freeman $M D^{1}$, Peter WC Kwan $M D^{1}$, James R Gray $M^{1}{ }^{1}$, Douglas Webber $M D^{2}$
}

\section{CASE PRESENTATION}

A 70-year-old Asian-born woman experienced intermittent melena and iron-deficiency anemia that was treated with long-term omeprazole and iron supplements. Previous studies in other hospitals in 2009 and 2010 revealed multiple hyperplastic gastric polyps in the gastric antrum and body, but no dysplasia. There was no known family history of gastric neoplasia or previous Helicobacter pylori infection. In 2012, she experienced an additional episode of melena. Gastroscopic evaluation confirmed the presence of multiple small and large gastric polyps, typical of hyperplastic polyps (1) (Figures 1A and 1B), some with focal erosions but no dysplasia, along with a superimposed large ulcerating and polypoid lesion in the gastric body consistent with a high-grade malignancy (Figures 2A and 2B). Routine immunostaining of these biopsies to exclude stromal tumours as well as tumours of smooth muscle and neural origin with CD-117, actin and S-100 were negative. Subtotal gastrectomy showed an anaplastic spindle and epithelioid neoplasm consistent with an undifferentiated high-grade sarcomatoid malignancy (sarcoma versus sarcomatoid carcinoma), but not a gastrointestinal stromal tumour (GIST), localized to the stomach without nodal or distant metastases. Extensive immunohistochemical staining for epithelial, neuroendocrine, hematopoietic and melanocyte differentiation on the resected gastric malignancy were negative. The following stains were all negative: CD117 and DOG1 for GIST; smooth muscle actin, desmin, caldesmon for leiomyosarcoma; S100, Melan A, HMB45 for malignant peripheral nerve sheath tumour, melanoma and PECOMA; CD31 and CD34 for angiosarcoma; synaptophysin, chromogranin and TTF1 for neuroendocrine differentiation; cytokeratins 7, 19, 20, Cam 5.2 and CDX-2 for epithelial differentiation; and CD45, CD20, CD3 and ALK1 for lymphoreticular origin.

\section{DISCUSSION}

Previous reports have emphasized the extreme rarity of hyperplastic gastric polyposis (2), but recognize that carcinomatous transformation may occur in isolated hyperplastic gastric polyps (3). To our knowledge, the high-grade sarcomatoid malignancy detected in the present case has not been previously recorded to complicate hyperplastic gastric polyposis.

Anemia and chronic iron deficiency are the most common clinical features of hyperplastic polyps, especially if multiple polyps are present or if a superimposed gastric malignant lesion develops (4). Although $H$ pylori may be important in the pathogenesis, the role of omeprazole is not clear. Fundic gland polyposis appears to be associated with long-term omeprazole use (5), while retrospective studies have suggested an increase in hyperplastic gastric polyps with chronic omeprazole use (6). Further prospective studies are needed.
Guidelines for subsequent evaluation are not well defined. A low but definite risk of malignancy occurs in hyperplastic polyps and gastric adenomas, particularly if $>2 \mathrm{~cm}$ in size, and up to $20 \%$ of

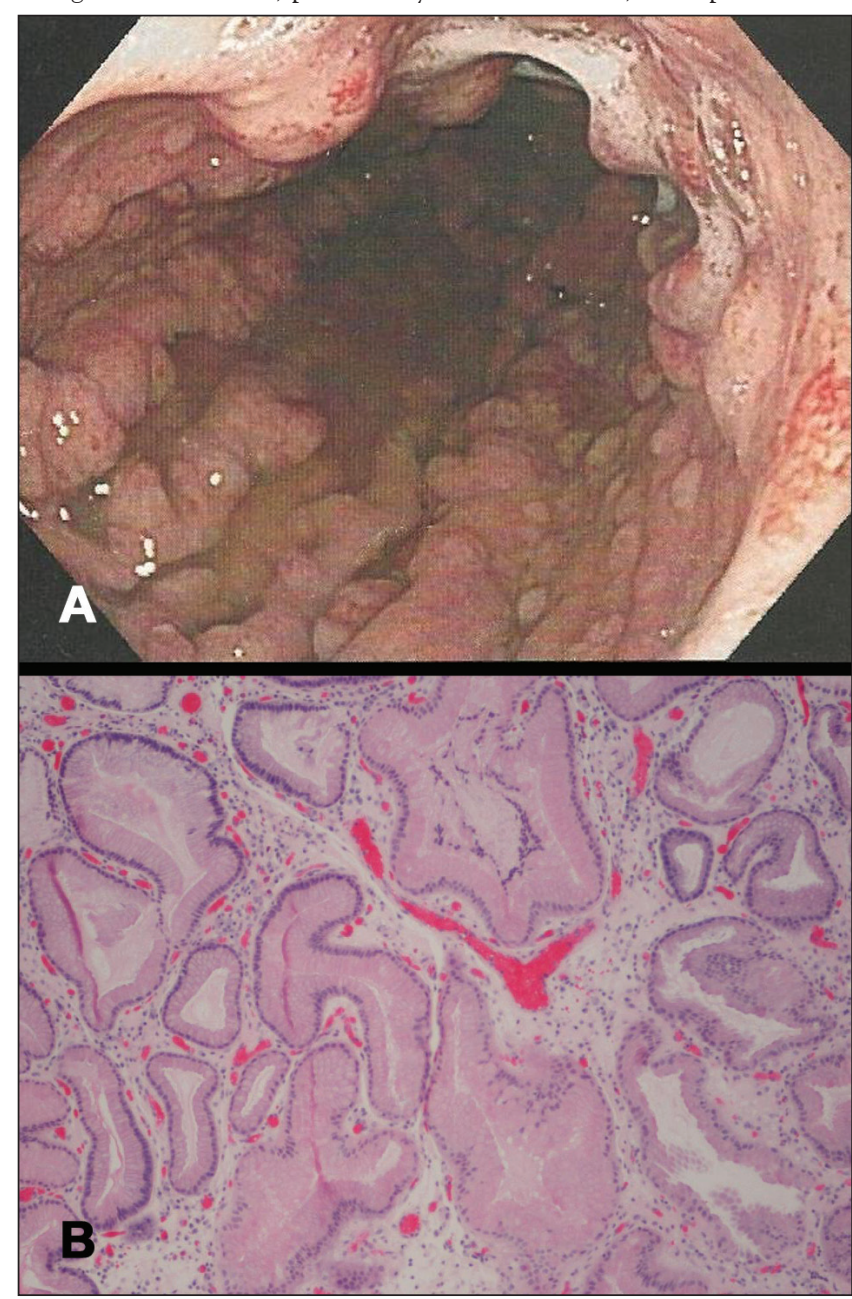

Figure 1) A Endoscopic view showing multiple gastric polyps. B Pathological changes confirming hyperplastic polyps with classic morphology including elongated foveolar epithelial-lined pits and no significant background inflammation. No foci of dysplasia were identified (hematoxylin and eosin stain, original magnification $\times 200$ )

${ }^{1}$ Departments of Medicine (Gastroenterology) and ${ }^{2}$ Pathology, University of British Columbia, Vancouver, British Columbia

Correspondence: Dr Hugh J Freeman, University of British Columbia Hospital, 2211 Wesbrook Mall, Vancouver, British Columbia V6T 1 W5 .

Telephone 604-822-7216,e-mail hugfree@shaw.ca

Received for publication January 24, 2014. Accepted February 7, 2014 

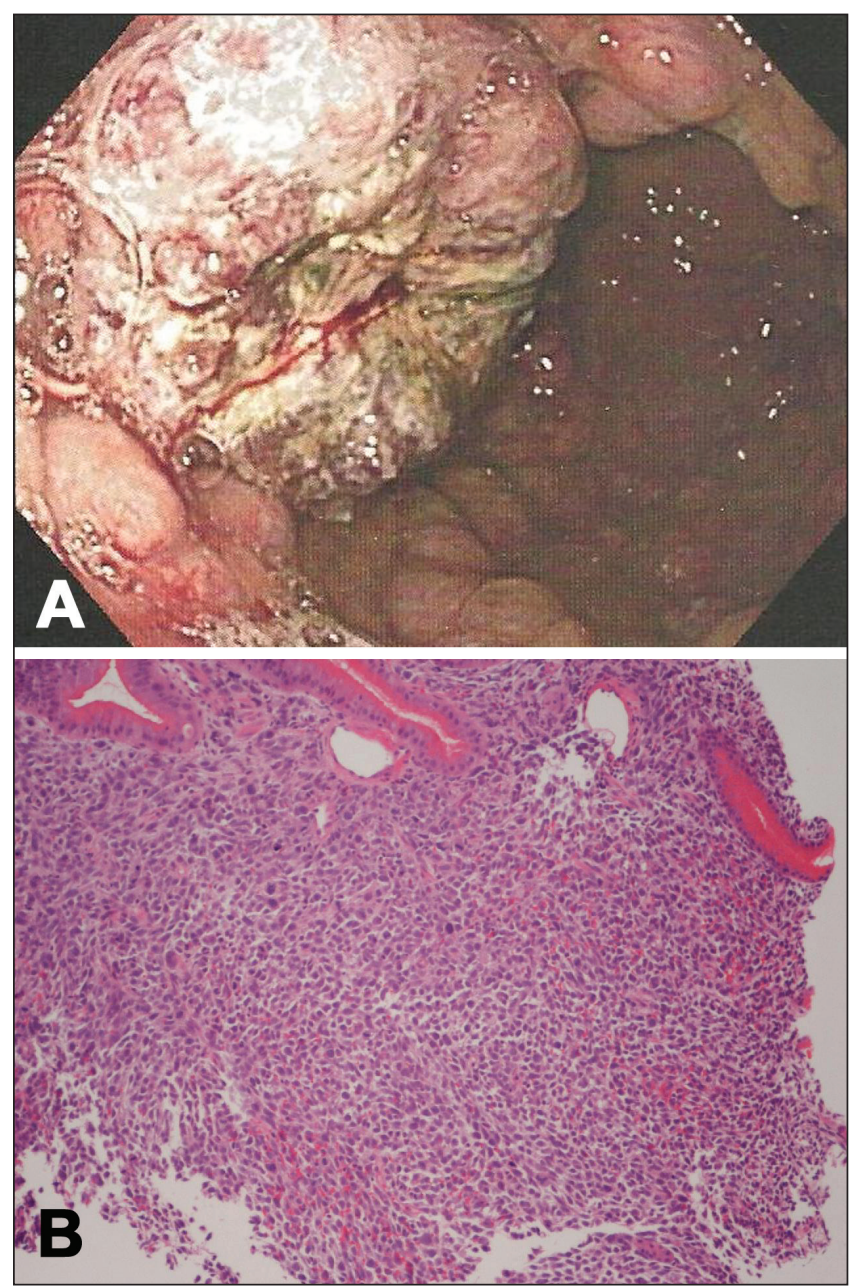

Figure 2) A Endoscopic view of polypoid ulcerated gastric neoplasm. B Pathological confirmation of undifferentiated malignant cells, focally spindled and focally epithelioid. Immunostains (see text) for stromal tumour, smooth muscle or neuroendocrine lesions negative (hematoxylin and eosin stain, original magnification $\times 200$ ) hyperplastic polyps have dysplastic foci (1). Gastric mapping for dysplasia may be considered if multiple hyperplastic polyps are present and, if dysplasia is discovered, individual screening protocols should be considered to obviate gastric cancer risk (4).

\section{REFERENCES}

1. Shaib YH, Rugge M, Graham DY, Genta RM. Management of gastric polyps: An endoscopy-based approach. Clin Gastroenterol Hepatol 2013;11:1374-84.

2. Rozas DA, Rackoff AI, Brady PG. Hyperplastic gastric polyposis: A rare entity. Clin Gastroenterol Hepatol 2010;8:e85

3. Diabo M, Itabashi M, Hirota T. Malignant transformation of gastric hyperplastic polyps. Am J Gastroenterol 1987;82:1016-25.

4. Carmack SW, Genta RM, Graham DY, Lauwers GY. Management of gastric polyps: A pathology-based guide for gastroenterologists. Nat Rev Gastroenterol Hepatol 2009;6:331-41.

5. Freeman HJ. Proton pump inhibitors and an emerging epidemic of gastric fundic gland polyposis. World J Gastroenterol 2008;14:1318-20.

6. Choudhry U, Boyce HW Jr, Coppola D. Proton pump inhibitorassociated gastric polyps: A retrospective analysis of their frequency, and endoscopic, histologic, and ultrastructural characteristics. Am J Clin Pathol 1998;110:615-21. 


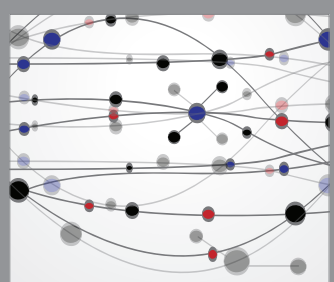

The Scientific World Journal
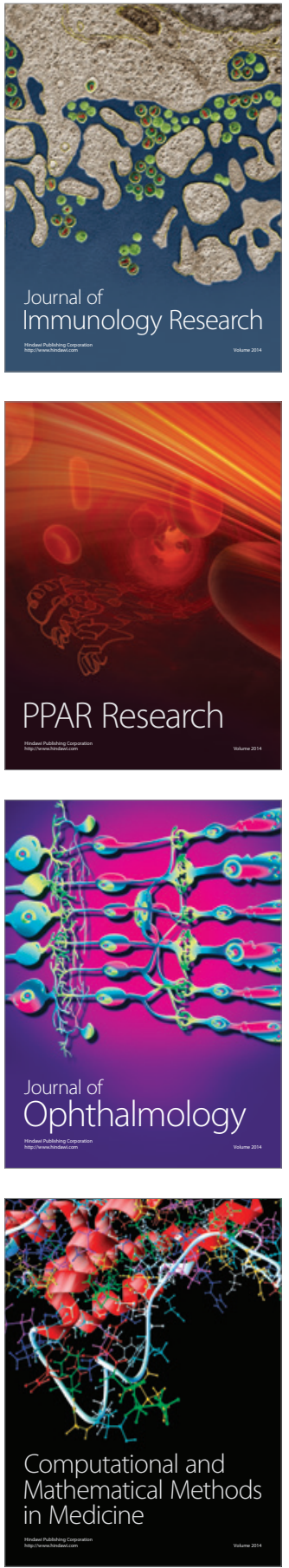

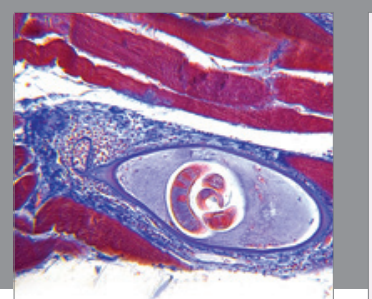

Gastroenterology Research and Practice

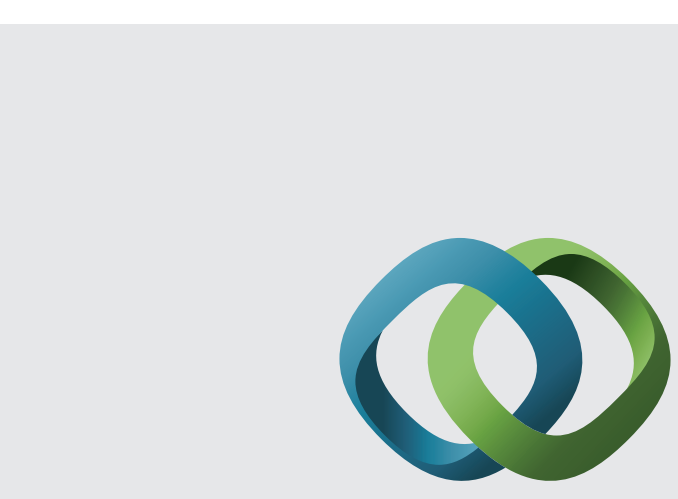

\section{Hindawi}

Submit your manuscripts at

http://www.hindawi.com
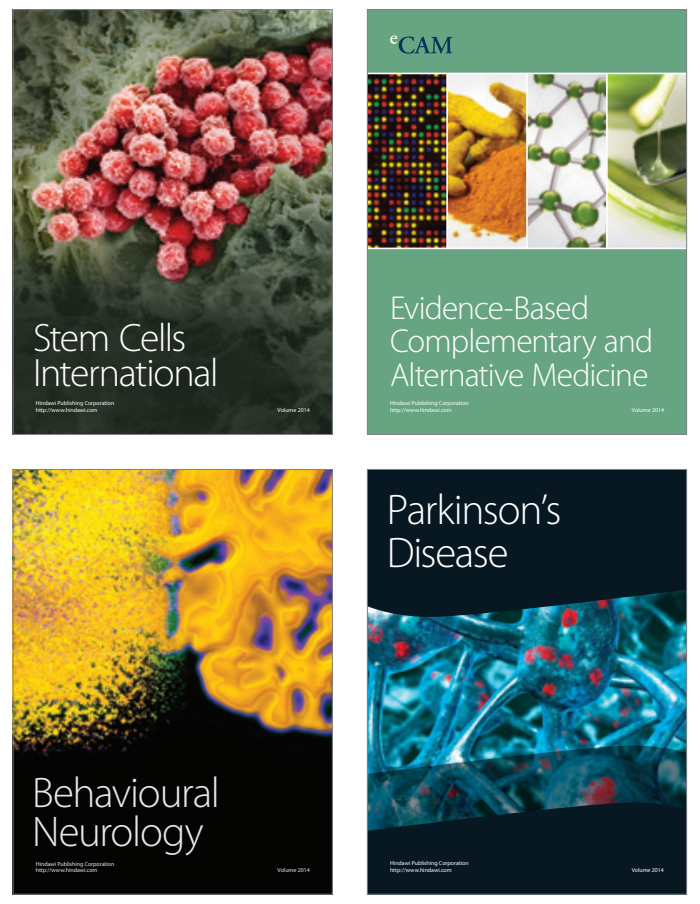
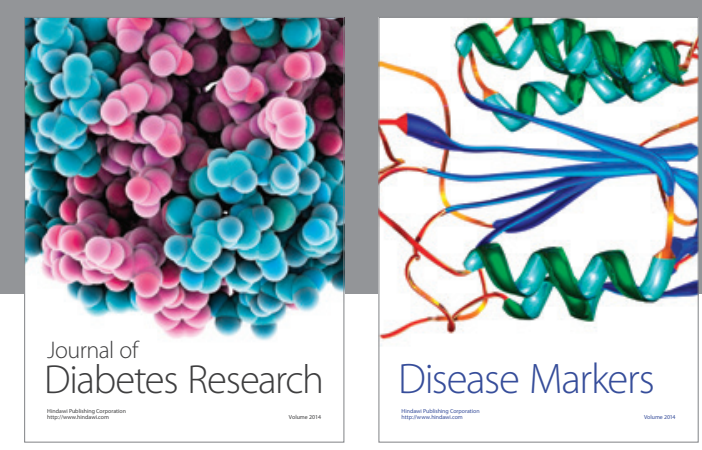

Disease Markers
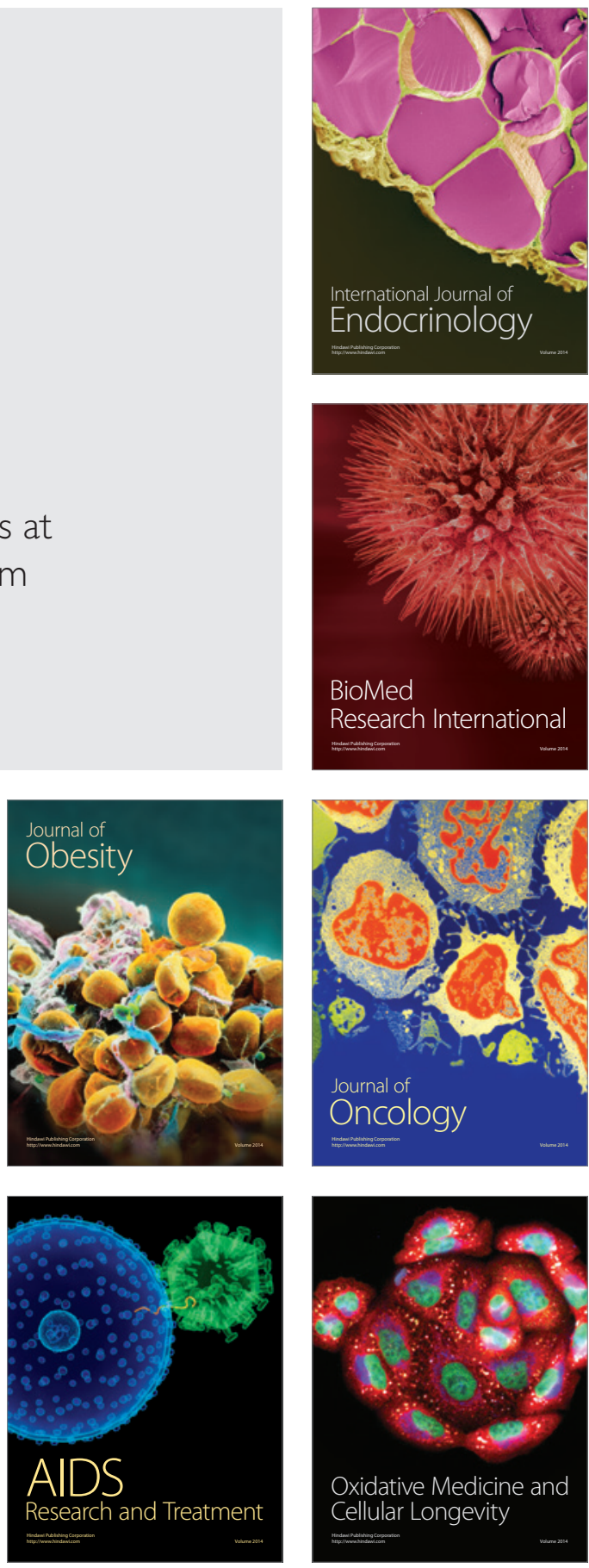